\title{
RADICALES LIBRES Y SISTEMA DE DEFENSA ANTIOXIDANTE
}

\author{
LIDIA CRUZ NEYRA \\ Facultad de Ciencias Biológicas, Universidad Ricardo Palma \& Facultad de Ciencias, \\ Universidad Nacional de Educación "Enrique Guzmán y Valle".
}

\section{RESUMEN}

Las moléculas altamente reactivas denominadas radicales libres pueden causar daño tisular por reaccionar con los ácidos grasos polisaturados de las membranas celulares, los nucleótidos del DNA y los grupos sulfidrilos críticos de las proteínas. Los radicales libres pueden originarse endógenamente a través de las reacciones metabólicas normales o exógenamente a través de los componentes del humo del cigarro, aire contaminado o indirectamente por el metabolismo de ciertos solventes, drogas y pesticidas o por exposición a la radiación. Existen evidencias que el daño por radicales libres está implicado con una variedad de eventos patológicos, como enfermedades cardiovasculares, inflamatorias, cataratas, cáncer y envejecimiento.

El sistema de defensa contra el daño celular por radicales libres incluye el tocoferol (vitamina E), el ácido ascórbico (vitamina C), Bcaroteno, glutation, ácido úrico, bilirubina y algunas metaloenzimas como glutation peroxidasa, catalasa y superóxido dismutasa. Así los micronutrientes antioxidantes pueden tener un papel protector contra los efectos adversos de la injuria oxidativa por radicales libres

Palabras claves: radicales libres $\cdot$ antioxidantes $\cdot$ micronutrientes $\cdot$ daño tisular

\section{SUMMARY}

Highly reactive molecules called free radicals can cause tissue damage by reacting with polyunsaturated fatty acids in cellular membranes, nucleotides in DNA and critical sulfhydryl bonds in proteins. Free radicals can originated endogenously from normal metabolic reactions or exogenously as components of tobacco smoke and air pollutants and indirectly through the metabolism of certain solvents, drugs and pesticides as well as through exposure to radiation.

There is some evidence that free radical damage has been implicated with a variety of pathological events, such as cardiovascular. inflammatory diseases, cataracts, cancer and aging.

Defenses against free radical damage include tocopherol (vitamin E), ascorbic acid (vitamin C), B-carotene, glutathione, uric acid, bilirubin and several metalloenzymes such as glutathione peroxidase, catalase and superoxide dismutase. Thus, these antioxidant micronutrients have the potential role protective against the adverse effects of oxidative injury.

Key words: · free radicals · antioxidants - micronutrients · tissue damage

\section{INTRODUCCIÓN}

Los radicales libres son especies químicas que tienen un electrón desapareado, muy inestables, con elevada afinidad para reaparearlo y anular su campo magnético, convirtiéndose en temible agresor. El daño celular por radicales libres puede ser evitado por ciertas enzimas y vitaminas con propiedades antioxidantes. La existencia de un daño celular será el resultado del balance entre los radicales libres generados y el sistema antioxidante.

El objetivo de esta revisión es identificar las fuentes de los radicales libres, sus reacciones con los componentes celulares, con énfasis en el papel que desempeñan los antioxidantes de la dieta.

\section{Fuente de radicales libres}

El oxígeno que respiramos está en estado fundamental y es un birradical. Su molécula presenta dos electrones desapareados y es muy estable, pero la adquisición de un electrón, a través de un aporte energético, puede aparear uno de sus electrones y convertirlo en anión superóxido, radical libre. (1).
El anión superóxido $\left(\mathrm{O}_{2}{ }^{-}\right)$, así representado, indica que tiene una carga negativa (signo «menos») y un electrón desapareado (denotado por un punto). La producción del anión superóxido es de origen enzimático, por ejemplo por la reacción catalizada por la xantina oxidasa. El anión superóxido puede tener un efecto destructor directo, cuando desestabiliza la estructura fosfolipoproteica de las membranas celulares, por ruptura de los enlaces ésteres de los ácidos grasos que conforman los fosfolípidos, o de manera indirecta generando el radical hidroxilo $\left(\mathrm{OH}^{\circ}\right)$, especie oxigenada extremadamente reactiva, capaz de atacar las estructuras orgánicas más estables.

La existencia del anión superóxido es muy corta, en presencia de iones $\mathrm{H}^{+}$, permite el fenómeno de dismutación en el cual una molécula de 02 - $^{-}$cede su electrón a otra formándose oxígeno fundamental y peróxido de hidrógeno $\left(\mathrm{H}_{2} \mathrm{O}_{2}\right)$. El peróxido de hidrógeno en presencia del ion ferroso $\mathrm{F}^{2} \mathrm{e}^{2+}$ sufre una reacción de Fenton (2), produciéndose el radical hidróxilo $0 \mathrm{H}^{*}$. Este último, otra especie reactiva del oxígeno, es capaz de generar una reacción en 
cadena, produciendo radicales peróxilos $\left(\mathrm{R} 00^{\circ}\right)$ alcohoxilos $\left(\mathrm{R} 0^{\circ}\right)$.

Los radicales libres intracelulares son generados en mitocondrias, lisosomas, peroxisomas, núcleo, retículo endoplásmico, membrana celular y en el citosol, por la actividad de ciertas oxidasas, ciclooxigenasas, lipoxigenasas, deshidrogenasas y peroxidasas. Siendo las oxidasas y el sistema de transporte de electrones, la continua fuente de radicales libres.

La fuente exógena de radicales libres incluye los compuestos del humo del cigarro, solventes orgánicos, anestésicos, pesticidas, como también ciertos medicamentos que son metabolizados produciendo radicales libres. La exposición a la radiación resulta en la formación de radicales libres en el tejido expuesto (3-6).

\section{Daño Tisular}

El primer blanco de acción de los radicales libres son los dobles enlaces en las membranas, consecuentemente, se produce peroxidación, pérdida de la fluidez de la membrana y potencialmente lisis celular. Los radicales libres reaccionan con las enzimas que contienen grupos sulfidrilos provocando inactivación y denaturación y con los ácidos nucleicos producen mutaciones del DNA, las cuales pueden ser carcinogénicas.

El daño oxidativo de los carbohidratos está asociado con las funciones de los receptores celulares en las respuestas hormonales y neurotransmisoras $(5,6)$.

Los radicales libres, tal como los radicales peroxilos, el anión superóxido y el radical hidroxilo son responsables de las reacciones de injuria celular. Además ciertos aldehído como el malondialdehido y el hidroxinonenal, productos de la degradación de ácidos grasos por radicales libres, pueden formar enlaces entrecruzados (cross-linking) con lípidos, proteínas y ácidos nucleicos (7).

\section{Defensa contra los radicales libres}

Diversos argumentos sustentan la hipótesis que los radicales libres se forman incesantemente en el interior de los tejidos vivos. ¿Cuáles son los medios de protección endógenos que la célula tiene para enfrentar esa agresión?

El primer medio endógeno de defensa natural está constituido por las Superoxido Dismutasas (SOD), enzimas que aceleran la velocidad de dismutación del anión superóxido a peróxido de hidrógeno. En mamíferos se conoce dos superóxido dismutasas, una localizada en las mitocondrias (metaloproteína que contiene manganeso) y la otra citoplasmática que contiene cobre y zinc.

Una segunda enzima es la catalasa que convierte el peróxido de hidrógeno en agua y oxígeno. La catalasa (contiene hierro) se localiza en los peroxisomas. Otra enzima capaz de destruir el peróxido de hidrógeno es la glutatión peroxidasa (GPO) que contiene selenio y se localiza en el citoplasma. Esta enzima necesita glutation como cofactor esencial.

El medio de defensa exógeno está conformado por substancias capaces de secuestrar o capturar los radicales libres, denominados antioxidantes, pues inhiben la reacción en cadena de los radicales libres. Un captador no es eficaz contra todos los radicales libres, existe un grado de especificidad que se explica por ciertas incompatibilidades estearicas o por diferencias de solubilidad. Cuando el radical libre es liposoluble y el elemento captador es hidrófilo no se produce la captura del radical libre.

De los nutrientes esenciales existe sólo tres que pueden secuestrar radicales libres. La vitamina $\mathrm{E}$ ( $\alpha$-tocoferol), el principal antioxidante liposoluble presente en las membranas celulares, protege contra la peroxidación de lípidos. La vitamina $E$ puede actuar directamente con varios radicales, como el radical peroxilo (R00) y el radical hidróxilo $(\mathrm{OH})$, como también con el anión superóxido $\left(\mathrm{O}_{2}{ }^{*}\right)$. El tocoferol puede reaccionar directamente con el oxígeno singlete $(8,9)$.

La deficiencia de vitamina E en animales aumenta la concentración de aldehídos y peróxidos en tejidos y niveles incrementados de etano y pentano exhalados (11).

La vitamina C (ácido ascórbico) es hidrosoluble, puede secuestrar radicales libres y oxígeno singlete. EL ácido ascórbico puede regenerar la forma reducida, antioxidante, de la vitamina E. En presencia de metales de transición, el ácido ascórbico puede provocar la formación de radicales libres sin embargo, no existen evidencias de autooxidación por efecto del ácido ascórbico (10).

Recientes trabajos han demostrado que el $\beta$-caroteno, un pigmento encontrado en plantas, es el mejor secuestrador del oxígeno singlete y también funciona como un antioxidante. $\beta$-caroteno es un precursor de la vitamina A, pero esta última no tiene capacidad de secuestrar radicales libres. $\beta$-caroteno ha sido encontrado en todas las membranas, incluyendo los lisosomas $(12,13)$. Los tres nutrientes mencionados se encuentran también en concentraciones relativamente altas en el suero.

Por otro lado, algunos minerales, nutricionalmente esenciales son cofactores de las enzimas antioxidantes. El zinc, cobre y manganeso son requeridos para la actividad enzimática de las superóxido dismutasas, selenio para la glutation peroxidasa y hierro, como grupo heme, para la catalasa $(14,15)$.

En conclusión, la oxidación de lípidos, proteínas, carbohidratos y ácidos nucleicos por radicales libres pueden producir daño en el sistema biológico; sin embargo, el sistema de defensa, que incluye enzimas y vitaminas antioxidantes, pueden proteger al organismo del efecto adverso de los radicales libres. No obstante, se necesita conocer mejor la bioquímica de las substancias tóxicas, oxígeno-reactivas para poder determinar los antioxidantes más apropiados para preservar la integridad de los tejidos. 


\section{REFERENCIAS BIBLIOGRÁFICAS}

1. FRIDOVICH, L. 1975. Superoxide dismutases. Ann. Rev. Biochem. 44, 19-43.

2. FEE, J.A.; VALENTINE, J.S. 1977. Chemical and physical properties of superoxide. In superoxide and superoxide dismutase. Michelson, A.M. Mc Cord, J.M; Fridovich, I. Eds. Academic Press., New York, 19-57.

3. TAYLOR, A.E. ; MATALON, S.; WARD, P.A.1986 Physiology of oxygen radicals. Bethesda. Am. Physiol. Soc.

4. HALLIWELL, B.; GUTTERIDGE, J.M.C. 1985. Free radicals in Biology and Medicine. Oxford, England.

5. SLATER, T.F. 1972. Free radical mechanism in tissue injury. London, Pion.

6. FREEMAN, B.A.; CRAPO, J.D. 1982. Biology of disease free radicals and tissue injury. Lab. Invest. 47:412-426.

7. FLOHE,L.; BECKMMANN,R.;GIERTZ,H.;LOSCHEN, G. 1985. Oxygen-centered free radicals as mediator of inflammation. In S., H. Ed. Oxidative Stress. Academic Press, New York, 405-437.

8. FAHRENHOLTZ, S.R.; DOLEIDEN, F.H.; TROZZOLO, A.M.; LAMOLA, A.A. 1974. On the quenching of singlet oxygen by alpha-tocopherol. Photochem. Photobiol. 20:505-509.

9. LITTARRU, G.P.; LIPPA, S., DE SOLE, P. ORADEI, A.; DALLA-TORRE, F., MACRI, M. 1984. Quenching of singlet oxygen by D-alpha-tocopherol in human granulocytes. Biochem. Biophys. Res. Commun. 119:1056-1061.

10. BENDICH, A., MACHLIN, L.J.; SCANDURRA, O.; BURTON, G.W.; WAYNER, D.M. 1986. The antioxidant role of vitamin C. Adv. Free Radical Biol. Med. 2:419444.

11. MACHLIM, L.; BENDICH, A. 1987. Free Radical Tissue damage: protective role of antioxidant Nutrients. FASEB, J. 1:441-445.

12. BURTON, G.W.; INGOLD, K.V. 1984. Beta-carotene. An unsual type of lipid antioxidant. Science 224: 569573.

13. MAYNE, S. T.; PARKER, R.S. 1986. Subcellular distribution of dietary beta carotene in chick liver. Lipids 21:164-169.

14. NIKI, E. ; YAMAMOTO, Y. ; KOMURO, E. ; SATO, K. 1991.

15. MEMBRANEDAMAGEDUE TOLIPID OXIDATION - AM. J. CLIN. NUTR. 53 : 201 S - 205 S.

16. THOMAS, M. 1995. The role of free radicals and antioxidants : How do we know that they are working? Critical Reviews in food Science and Nutrition 35:2139. 